\title{
Lower Likelihood of Burnout Among Family Physicians From Underrepresented Racial-Ethnic Groups
}

\author{
Montgomery Douglas, $M D^{1}$ \\ Emil Coman, PbD, PStat ${ }^{2}$ \\ Aimee R. Eden, $\mathrm{PbD}, M P H^{3}$ \\ Suleiman Abiola ${ }^{1}$ \\ Kevin Grumbach, $M D^{4}$
}

'Department of Family Medicine, University of Connecticut School of Medicine, Farmington, Connecticut

${ }^{2}$ Health Disparities Institute, University of Connecticut School of Medicine, Farmington, Connecticut

${ }^{3}$ American Board of Family Medicine, Lexington, Kentucky

${ }^{4}$ Department of Family and Community Medicine, University of California, San Francisco, California
Conflicts of interest: Aimee Eden is employed by the American Board of Family Medicine. There are no other conflicts of interest to declare.

\section{CORRESPONDING AUTHOR}

Montgomery Douglas

Dept of Family and Community Medicine SUNY Downstate Health

Sciences University

450 Clarkson Ave

Brooklyn, NY 11203

Montgomery.Douglas@downstate.edu

\begin{abstract}
PURPOSE We investigated whether physician race and ethnicity were associated with burnout among a nationally representative sample of family physicians.

METHODS We undertook a cross-sectional observational study using survey data from 1,510 American Board of Family Medicine recertification applicants in 2017 and 1,586 respondents to the 2017 National Graduate Survey. Of the 3,096 total family physicians, $450(15 \%)$ were from racial and ethnic groups underrepresented in medicine. We used structural equation models to test the effects of underrepresented status on single-item measures of emotional exhaustion and depersonalization.
\end{abstract}

RESULTS Family physicians underrepresented in medicine were significantly less likely than their non-underrepresented counterparts to report emotional exhaustion (adjusted odds ratio $=0.82 ; 95 \% \mathrm{Cl}, 0.69-0.99$; total effect) and depersonalization (adjusted odds ratio $=0.54 ; 95 \% \mathrm{Cl}, 0.41-0.71$; total effect). The underrepresented physicians were more likely than non-underrepresented peers to practice in more racially and ethnically diverse counties and less likely to practice obstetrics, both of which partly mediated the protective effect of underrepresented status on depersonalization.

CONCLUSIONS Although factors such as racism might be expected to adversely affect the well-being of underrepresented clinicians, underrepresented family physicians reported a lower frequency of emotional exhaustion and depersonalization. The mediating protective effect of working in more racially and ethnically diverse counties is consistent with evidence of the beneficial effect of cultural diversity on health outcomes for minorities. Because physician burnout is a known predictor of job turnover and may also be associated with poorer quality of care, the lower burnout observed among underrepresented family physicians may be an asset for the health care system as a whole.

Ann Fam Med 2021;19:342-350. https://doi.org/10.1370/afm.2696.

\section{INTRODUCTION}

Burnout is defined as "feeling empty and mentally exhausted, devoid of motivation, and beyond caring."1 One commonly used conceptual framework considers burnout to consist of 3 dimensions: emotional exhaustion, depersonalization, and reduced personal accomplishment. ${ }^{2}$ More than $40 \%$ of US physicians reported at least 1 symptom of burnout, ${ }^{3}$ and the prevalence is particularly high among family physicians. ${ }^{3-5}$ The consequences of physician burnout include increased relationship conflicts, ${ }^{6}$ job turnover and early retirement, ${ }^{7}$ reduced productivity ${ }_{1}^{8}$ decreased safetyrelated quality of care, ${ }^{9-11}$ and lower patient satisfaction. ${ }^{12,13}$ Various workrelated factors have been shown to contribute to burnout among family physicians, including work environment-related stressors, ${ }^{5,14}$ constricted scope of practice, ${ }_{1}^{15}$ and limited clinic resources to address social determinants of health. ${ }^{16,17}$ Some physician characteristics are also associated with burnout, with studies consistently finding a higher rate among women than men, and among US medical graduates compared with international medical graduates. ${ }^{3,18}$ 
Despite a growing body of literature on predictors of physician burnout, few studies have focused specifically on whether physician race and ethnicity are associated with burnout. A study of a sample of family medicine residents and faculty in Texas reported that non-Hispanic White ethnicity was associated with a higher likelihood of 2 dimensions of burnout: emotional exhaustion and depersonalization. ${ }^{19}$ An earlier study of family medicine residents in South Carolina found that rates of depersonalization increased during training among White but not Black residents. ${ }^{20}$ Some studies focusing on work environment predictors of burnout using nationally representative samples of family physicians have mentioned adjusting for physician race and ethnicity in their analytic models, but did not specifically report results for the race and ethnicity predictor in multivariate models. ${ }^{14-16} \mathrm{~A}$ recently published study of a national sample of US physicians found lower odds of burnout among Black, Latino, and Asian physicians relative to White physicians overall, but did not examine this association within individual specialties such as family medicine. ${ }^{21}$

We conducted a study of a national sample of family physicians to determine whether the frequency of experiencing burnout differed among those from racial and ethnic groups underrepresented in medicine (hereafter underrepresented) compared with peers from groups not underrepresented. The Association of American Medical Colleges uses the term underrepresented in medicine to refer to racial and ethnic groups who have disproportionately low representation in the profession relative to their proportion in the general population. ${ }^{22}$ Groups underrepresented in medicine include Blacks/ African Americans, Hispanics/Latinos, American Indians, and Pacific Islanders, who together comprise $30.5 \%$ of the general population yet account for only $12.4 \%$ of family physicians. ${ }^{23}$

It is important to know whether the experience of burnout differs among practicing family physicians according to underrepresentation status in a sample that is nationally representative, and not just for residents or physicians from a single state. Factors such as experiences of racism may exert a cumulative toll on the well-being of underrepresented physicians, causing these clinicians to be more susceptible to burnout over time after completing residency. On the other hand, some underrepresented physicians' characteristics may mitigate against burnout. ${ }^{24}$ Among medical students, greater altruism and sense of social responsibility are associated with a lower likelihood of reporting burnout. ${ }^{25}$ Underrepresented medical students are more likely than non-underrepresented peers at matriculation to report an intent to work in underserved communities, ${ }^{26}$ and underrepresented physicians are more likely to practice primary care and serve in underserved communities than non-underrepresented counterparts, ${ }^{23,27}$ reflecting a social mission orientation that may protect against burnout.

We hypothesized that underrepresented family physicians would experience burnout less often than their non-underrepresented counterparts. Moreover, greater community diversity has been shown to be associated with a higher level of well-being among community members, such as more positive developmental attributes among Black youth ${ }^{28}$ and better overall self-rated health among adults, ${ }^{29}$ providing a rationale for including community diversity as a potential mediator in our study. Serving in more diverse regions is expected to protect against burnout by preventing the onset of the exhaustion stage as theorized by Selye ${ }^{30}$ in his stress models, a phenomenon he termed the general adaptation syndrome. A sense of service ${ }^{31}$ provides more meaning to one's work, ${ }^{32}$ increases satisfaction with one's work, ${ }^{33}$ and reduces career choice regret. ${ }^{34}$ This protective effect occurs by potentially preventing feelings of self-depletion ${ }^{33}$ when altruistically serving patients with more diverse needs and expectations.

A secondary aim of our study was to explore other potential mediators of the effect of underrepresentation status and burnout, such as practicing obstetrics, or providing pediatric or adult hospital care.

\section{METHODS}

This cross-sectional observational study used survey data from the 2017 American Board of Family Medicine (ABFM) Family Medicine Continuing Certification Examination Registration questionnaire, and from the 2017 National Graduate Survey (NGS). Completion of the former is a mandatory step for examination registration that occurs 3 to 4 months before the examination date and thus has a $100 \%$ response rate. The NGS is a voluntary postgraduate follow-up survey for recent graduates of family medicine residency programs; the 2017 survey was directed at 2014 graduates and garnered a $65 \%$ response rate. We excluded respondents who did not provide outpatient continuity care. The study was reviewed by the University of Connecticut School of Medicine Institutional Review Board, and adjudged to be exempt.

In the 2017 ABFM continuing certification process, all applicants completed a core set of questions, which included items on self-designated race (response options are American Indian or Alaska Native, Asian, Black or African American, Native Hawaiian or Other Pacific Islander, White, or Other) and ethnicity (Hispanic or Latino, with response options of yes and no). 
NGS respondents completed the same questions about their race and ethnicity. Consistent with the American Association of Medical Colleges definition, we categorized applicants as underrepresented in medicine if they self-reported any of the following races and/ or ethnicities: Black/African American, American Indian/Alaskan, Native Hawaiian/Pacific Islander, and Hispanic/Latino. All others were categorized as nonunderrepresented. From the core set, we also obtained data on applicant sex, age, degree (doctor of medicine $[\mathrm{MD}]$ or doctor of osteopathic medicine $[\mathrm{DO}]$ ), medical school location (United States or elsewhere), practice size, and practice scope.

For the Continuing Certification Examination Registration questionnaire, applicants were randomized to one of several modules, one of which included singleitem measures of emotional exhaustion and depersonalization that have been shown to be valid predictors of scores on these domains on the multi-item Maslach Burnout Inventory subscales. ${ }^{35,36}$ All NGS respondents also received these same single-item measures of emotional exhaustion and depersonalization. The questionnaires had 7 response options for these items: never, a few times a year or less, once a month or less, a few times a month, once a week, a few times per week, and every day. Consistent with prior studies, ${ }^{36}$ we classified physicians responding once a week or more as having a high level of burnout to analyze the outcomes as dichotomous outcomes. Although being burned out can be assessed by either emotional exhaustion or depersonalization, ${ }^{21}$ these are distinct dimensions of burnout ${ }^{37}$ and have distinct triggers and effects ${ }^{38}$; therefore, we analyzed them as separate outcomes.

We used the applicant's practice address to geocode each applicant to a county and link the applicant to a county-level database on population diversity available from PolicyMap. ${ }^{39}$ The PolicyMap diversity index (DI) indicates the probability that 2 individuals randomly selected from the same county would be of different race-ethnicity, based on 8 mutually exclusive racialethnic categories measured from US Census data. The DI ranges from 0 to 1 , with lower index values $(0$ to 0.2 ) suggesting more homogeneity and higher index values (greater than 0.5) suggesting more heterogeneity. A county with a predominant race-ethnicity group among its residents will have a low DI, and one with a relatively even distribution among the race-ethnicity groups will have a high DI.

We compared crude rates of emotional exhaustion and depersonalization between family physicians who were and were not underrepresented in medicine using $\chi^{2}$ tests for these measures categorized as dichotomous (high vs not-high emotional exhaustion or depersonalization) and $\chi^{2}$ differences tests for the same items measured as continuous variables. We included the dichotomous categorization only in crude analyses and not in adjusted (multivariate) analyses, for ease of interpretation and comparability to results from other burnout studies using dichotomous classifications, despite the sacrifice in capturing gradations of burnout when converting continuous variables to dichotomous categories. We used structural equation models ${ }^{40}$ in Stata (StataCorp LLC) using the gsem command for continuous outcomes to test for differences between underrepresented and non-underrepresented groups in their degree of emotional exhaustion and depersonalization, controlling for other potential confounding demographic and practice variables and the county DI. For ordinal outcome measures, the odds ratios were estimated in one global model as a single value for all 6 comparisons (ie, "never" vs all other frequencies, "less than a few times a year" vs all other higher frequencies, etc), similar to a logit model comparing yes vs no categories. The continuous outcome models are more precise because they model the degrees of emotional exhaustion and depersonalization (how often they occur), compared with analyzing them as mere yes vs no dichotomous outcomes (whether they occurred vs not).

We report the results of unadjusted comparisons as well as adjusted ones that controlled for potential confounders and mediators. The adjusted regression models included covariates that have been used in recent family medicine physician burnout studies: age, sex, degree (MD vs DO), practicing obstetrics, and providing pediatric care and adult hospital care. ${ }^{15}$ The adjusted underrepresented group odds ratios represent the direct effects on the 2 outcomes, emotional exhaustion and depersonalization. Yet, in many instances, covariates can theoretically be justified to act instead as mediators; that is, they may be an outcome of the primary predictor of interest (in this case, underrepresentation status) and impact the outcome of interest, and thus act as mediators and not simply copredictors. Modeling a mediator as a copredictor instead is a causal misspecification that can introduce bias in estimates of effects. ${ }^{41}$ We explored several potential mediators and found 2 of them to have indirect effects: the county DI and obstetrics practice. These mediators were selected because both a priori hypotheses about the community of practice and scope of practice being potential mediators, and results from our basic exploratory models which supported specifying them as mediators. For mediation tests, we used structural equation models ${ }^{42,43}$ for continuous outcomes, which generate estimates for the direct, indirect (as mediated by DI or obstetric practice), and total effect of underrepresented status on emotional exhaustion and depersonalization. Analysis codes and outputs 
are available online (https://bit.ly/ burnout_familymed).

\section{RESULTS}

A total of 1,510 ABFM recertification applicants completed the module on burnout, and 1,586 NGS respondents completed the survey containing burnout questions. Of the 3,096 total family physicians, $450(15 \%)$ were underrepresented in medicine. Compared with non-underrepresented peers, underrepresented physicians were significantly more likely to be women, speak Spanish, and have an MD rather than a DO degree (Table 1). A smaller proportion of the underrepresented group provided obstetrical care $(6.4 \%$ vs $13.6 \%, P<.001)$. The mean DI of the county of practice was greater for underrepresented vs non-underrepresented physicians ( 0.53 vs $0.44, P<.001)$. When the burnout measures were analyzed as dichotomous outcomes, underrepresented physicians were significantly less likely than non-underrepresented peers to report depersonalization once a week or more $(16.7 \%$ vs $21.1 \%$, $P=.03)$ but similarly likely to experience emotional exhaustion once a week or more $(38.0 \%$ vs $42.3 \%, P=.09$ ).

In unadjusted models without any covariates that analyzed the outcomes as continuous variables, underrepresented family physicians significantly less often reported experiencing emotional exhaustion $(\mathrm{OR}=0.83 ; 95 \% \mathrm{CI}$, 0.69-0.99) and depersonalization $(\mathrm{OR}=0.70 ; 95 \% \mathrm{CI}, 0.58-0.84)$ (Table 2). When covariates and mediators were added, underrepresentation no longer significantly directly predicted emotional exhaustion $(\mathrm{OR}=0.85 ; 95 \% \mathrm{CI}$, $0.71-1.02)$, but it remained a significant direct predictor of depersonalization $(\mathrm{OR}=0.74 ; 95 \% \mathrm{CI}$,

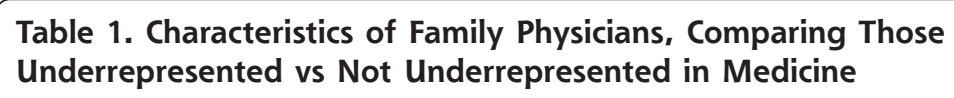

\begin{tabular}{|c|c|c|c|c|}
\hline \multirow[b]{2}{*}{ Characteristic } & \multirow{2}{*}{$\begin{array}{c}\text { All } \\
\text { Physicians } \\
(\mathrm{N}=3,096)\end{array}$} & \multicolumn{3}{|c|}{ Underrepresented in Medicine } \\
\hline & & $\begin{array}{c}\text { No } \\
(n=2,646)\end{array}$ & $\begin{array}{c}\text { Yes } \\
(n=450)\end{array}$ & $\begin{array}{c}P \\
\text { Value }\end{array}$ \\
\hline $\begin{array}{l}\text { Survey respondent group, } \\
\text { No. (\%) }\end{array}$ & & & & .08 \\
\hline Recertification & $1,510(48.8)$ & $1,308(86.6)$ & $202(13.4)$ & \\
\hline Graduate & $1,586(51.2)$ & $1,338(84.4)$ & $248(15.6)$ & \\
\hline Female, No. (\%) & $1,598(51.6)$ & $1,343(50.8)$ & $255(56.7)$ & .02 \\
\hline Ethnicity: Hispanic, No. (\%) & $231(7.5)$ & $0(0)$ & $231(51.3)$ & $<.001$ \\
\hline \multicolumn{5}{|l|}{ Race, No. (\%) } \\
\hline Black & $204(6.6)$ & $0(0)$ & $204(45.3)$ & $<.001$ \\
\hline $\begin{array}{l}\text { American Indian/Alaskan } \\
\text { Native }\end{array}$ & $30(0.9)$ & $0(0)$ & $30(6.7)$ & $<.001$ \\
\hline Speaks Spanish, No. (\%) & $324(10.5)$ & $222(8.4)$ & $102(22.7)$ & $<.001$ \\
\hline $\begin{array}{l}\text { Degree: MD (vs DO), No. } \\
(\%)\end{array}$ & $2,655(85.8)$ & $2,234(84.4)$ & $421(93.6)$ & $<.001$ \\
\hline $\begin{array}{l}\text { International medical grad- } \\
\text { uate, No. (\%) }\end{array}$ & $807(26.1)$ & $641(24.2)$ & $166(36.9)$ & $<.001$ \\
\hline Age, mean (SD), y & $\begin{array}{c}43.4 \\
(10.5)\end{array}$ & $\begin{array}{c}43.5 \\
(10.6)\end{array}$ & $\begin{array}{l}43.3 \\
(10.0)\end{array}$ & .73 \\
\hline \multicolumn{5}{|l|}{ Practice size, No. (\%) } \\
\hline Solo & $264(8.5)$ & $210(7.9)$ & $54(12.0)$ & .006 \\
\hline 2-5 clinicians & $2,063(66.6)$ & $1,759(66.5)$ & $304(67.6)$ & \\
\hline 6-20 clinicians & $462(14.9)$ & $411(15.5)$ & $51(11.3)$ & \\
\hline$\geq 21$ clinicians & $307(9.9)$ & $266(10.1)$ & $41(9.1)$ & \\
\hline $\begin{array}{l}\text { Pediatric inpatient care, } \\
\text { No. (\%) }\end{array}$ & $492(15.9)$ & $446(16.9)$ & $46(10.2)$ & $<.001$ \\
\hline Obstetric care, No. (\%) & $390(12.6)$ & $361(13.6)$ & $29(6.4)$ & $<.001$ \\
\hline $\begin{array}{l}\text { Adult inpatient care, } \\
\text { No. (\%) }\end{array}$ & $896(28.9)$ & $780(29.5)$ & $116(25.8)$ & .11 \\
\hline $\begin{array}{l}\text { County diversity index, } \\
\text { mean (SD) }\end{array}$ & $\begin{array}{c}0.46 \\
(0.18)\end{array}$ & $\begin{array}{l}0.44 \\
(0.18)\end{array}$ & $\begin{array}{l}0.53 \\
(0.16)\end{array}$ & $<.001$ \\
\hline \multicolumn{5}{|l|}{ Emotional exhaustion, No. (\%) } \\
\hline $\begin{array}{l}\text { Dichotomous: more than once } \\
\text { a week }\end{array}$ & $1,289(41.6)$ & $1,118(42.3)$ & $171(38.0)$ & .09 \\
\hline Categorical & & & & .07 \\
\hline Never & $177(5.7)$ & $147(5.6)$ & $30(6.7)$ & \\
\hline A few times a year & $421(13.6)$ & $340(12.9)$ & $81(18.0)$ & \\
\hline Once a month or less & $421(13.6)$ & $364(13.8)$ & $57(12.7)$ & \\
\hline A few times a month & $788(25.5)$ & $677(25.6)$ & $111(24.7)$ & \\
\hline Once a week & 399 (12.9) & $352(13.3)$ & $47(10.4)$ & \\
\hline A few times per week & $654(21.1)$ & $565(21.4)$ & $89(19.8)$ & \\
\hline Every day & $236(7.6)$ & $201(7.6)$ & $35(7.8)$ & \\
\hline \multicolumn{5}{|l|}{ Depersonalization, No. (\%) } \\
\hline $\begin{array}{l}\text { Dichotomous: more than once } \\
\text { a week }\end{array}$ & $634(20.5)$ & $559(21.1)$ & $75(16.7)$ & .03 \\
\hline Categorical & & & & .001 \\
\hline Never & $908(29.3)$ & $738(27.9)$ & $170(37.8)$ & \\
\hline A few times a year & $631(20.4)$ & $542(20.5)$ & $89(19.8)$ & \\
\hline Once a month or less & $484(15.6)$ & $430(16.3)$ & $54(12.0)$ & \\
\hline A few times a month & $439(14.2)$ & $377(14.3)$ & $62(13.8)$ & \\
\hline Once a week & $231(7.5)$ & $207(7.8)$ & $24(5.3)$ & \\
\hline A few times per week & $316(10.2)$ & $278(10.5)$ & $38(8.4)$ & \\
\hline Every day & $87(2.8)$ & $74(2.8)$ & $13(2.9)$ & \\
\hline
\end{tabular}


0.62-0.90). In the adjusted models, covariates that were significant predictors included age, DI (those practicing in counties with a higher DI had less emotional exhaustion and depersonalization), obstetrics practice (those practicing obstetrics had more depersonalization), and adult hospital practice (those practicing hospital medicine had less emotional exhaustion and depersonalization).

The models showed significant total effects of being underrepresented vs non-underrepresented on emotional exhaustion $(\mathrm{OR}=0.82 ; 95 \% \mathrm{CI}, 0.69-0.99)$ and depersonalization $(\mathrm{OR}=0.54 ; 95 \% \mathrm{CI}, 0.41-0.71)$, and mediating effects of both DI and obstetrical practice for underrepresented status effects on depersonalization (Figures 1 and 2, Table 2). Findings differed somewhat for the 2 outcomes, however.

Although the total effect of underrepresented status on emotional exhaustion was statistically significant, the mediating effect of underrepresented physicians practicing in more diverse counties did not reach statistical significance $(P=.063 ; \mathrm{OR}=0.97 ; 95 \% \mathrm{CI}$, 0.94-1.00) (Figure 1 and Table 2). Obstetrical practice was not a significant mediator. In the path model, the direct effect of underrepresented status on emotional exhaustion was not statistically significant $(P=.076$; $\mathrm{OR}=0.85 ; 95 \% \mathrm{CI}, 0.71-1.02$ ).

A slightly different pattern was observed for depersonalization. The model for this outcome showed that because underrepresented physicians practiced in more diverse counties (working in counties more diverse by $8.9 \%$, on average), they were less likely than non-underrepresented peers to report frequent depersonalization (indirect effect $\mathrm{OR}=0.94 ; 95 \%$ CI, 0.91-0.97) (Figure 2 and Table 2). Because underrepresented physicians were less likely to practice obstetrics, they were less likely to report frequent depersonalization (indirect effect $\mathrm{OR}=0.77 ; 95 \%$ CI, 0.62-0.95). Underrepresented status also had a direct effect on depersonalization, independent of DI and obstetric practice $(\mathrm{OR}=0.74 ; 95 \%$ CI, 0.62-0.90).

To test whether our results would change if we treated emotional exhaustion and depersonalization as dichotomous rather than continuous variables, we repeated our models using experience of these outcomes once a week or more, as compared with less often. ${ }^{3}$ Results were similar to those from the models for continuous outcomes, and the adjusted prevalences were nearly identical to the unadjusted ones reported in Table 1 (data not shown).

\section{DISCUSSION}

Among our nationally representative group of family physicians in all career stages, those underrepresented in medicine were less likely to report emotional exhaustion and depersonalization than their nonunderrepresented counterparts. The total protective effects of underrepresented status on emotional exhaustion and depersonalization were statistically significant in all the models we tested. The independent direct effect of being underrepresented on emotional exhaustion was not significant in the adjusted models, but the total effect of being underrepresented on emotional exhaustion was significant when accounting for mediation by county diversity.

Individuals from underrepresented backgrounds may face unique challenges in their life experiences and professional careers because of the adverse effects of interpersonal and structural racism and other forms

\begin{tabular}{|c|c|c|c|c|}
\hline \multirow[b]{2}{*}{ Model and Predictors } & \multicolumn{2}{|c|}{ Emotional Exhaustion } & \multicolumn{2}{|c|}{ Depersonalization } \\
\hline & OR $(95 \% \mathrm{Cl})$ & $P$ Value & OR $(95 \% \mathrm{Cl})$ & $P$ Value \\
\hline \multicolumn{5}{|l|}{ Unadjusted regression model } \\
\hline $\begin{array}{l}\text { Underrepresented in medicine (ref- } \\
\text { erent: not underrepresented) }\end{array}$ & $0.83(0.69-0.99)$ & .04 & $0.70(0.58-0.84)$ & $<.001$ \\
\hline \multicolumn{5}{|l|}{ Adjusted regression model } \\
\hline $\begin{array}{l}\text { Underrepresented in medicine (ref- } \\
\text { erent: not underrepresented) }\end{array}$ & $0.85(0.71-1.02)$ & .08 & $0.74(0.62-0.90)$ & .002 \\
\hline Practices obstetrics & $1.28(0.99-1.52)$ & .06 & $1.38(1.11-1.71)$ & .004 \\
\hline DI (per 10\%) & $0.97(0.93-1.00)$ & .058 & $0.93(0.90-0.97)$ & .000 \\
\hline Age (per 10 years) & $0.89(0.84-0.95)$ & $<.001$ & $0.65(0.61-0.70)$ & .000 \\
\hline Female (referent: male) & $1.43(1.26-1.63)$ & $<.001$ & $1.10(0.96-1.25)$ & .17 \\
\hline MD (referent: DO) & $1.06(0.89-1.27)$ & .51 & $0.96(0.80-1.15)$ & .64 \\
\hline Practices pediatric care & $1.09(0.88-1.34)$ & .43 & $1.13(0.92-1.40)$ & .25 \\
\hline Practices adult hospital care & $0.79(0.68-0.93)$ & .004 & $0.83(0.71-0.98)$ & .03 \\
\hline \multicolumn{5}{|l|}{ Path model testing for mediation } \\
\hline $\begin{array}{l}\text { Indirect effects mediated by under- } \\
\text { represented physicians being less } \\
\text { likely to practice obstetrics }\end{array}$ & $\cdots$ & $\cdots$ & $0.77(0.62-0.95)$ & .02 \\
\hline $\begin{array}{l}\text { Indirect effects mediated by under- } \\
\text { represented physicians practicing } \\
\text { in counties with higher DI }\end{array}$ & $0.97(0.94-1.00)$ & .06 & $0.94(0.91-0.97)$ & $<.001$ \\
\hline $\begin{array}{l}\text { Total effect of underrepresented } \\
\text { status (direct + indirect effects) }\end{array}$ & $0.82(0.69-0.99)$ & .03 & $0.54(0.41-0.71)$ & $<.001$ \\
\hline
\end{tabular}


of social inequity. Experiencing racial discrimination and related inequities contributes to adverse health outcomes among Black individuals. ${ }^{44}$ Although underrepresented medical students overall are less likely to feel burned out, they are more likely than non-underrepresented peers to report that their race-ethnicity adversely affected their medical school experience because of racial discrimination, racial prejudice,

\section{Figure 1. Potential mediating effect of county diversity index on the effect of underrepresented status on emotional exhaustion.}

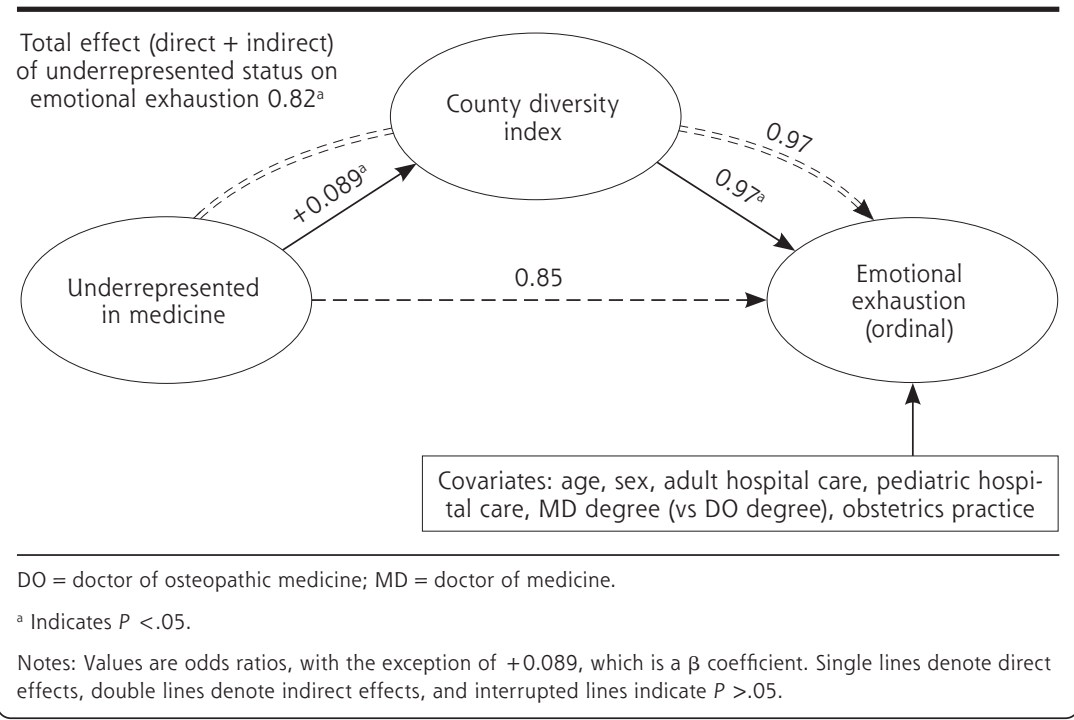

Figure 2. Mediating effects of county diversity index and practicing obstetrics on the effect of underrepresented status on depersonalization.

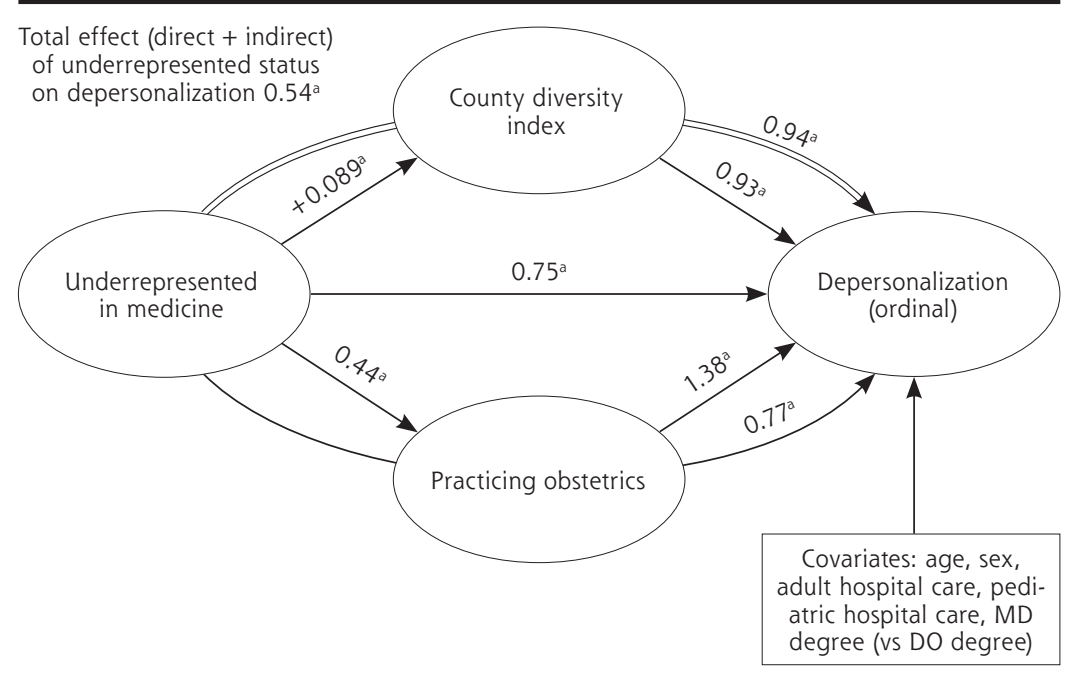

$\mathrm{DO}=$ doctor of osteopathic medicine; $\mathrm{MD}=$ doctor of medicine.

a Indicates $P<.05$.

Note: Values are odds ratios, with the exception of +0.089 , which is a $\beta$ coefficient. Single lines denote direct effects, and double lines denote indirect effects. feelings of isolation, and different cultural experiences. ${ }^{45}$ Minority students who reported these events were more likely to experience burnout and depressive symptoms, and had lower mental quality of life scores compared with minorities without adverse experiences. ${ }^{45}$ Although it might be expected that stress related to these same social factors would result in underrepresented physicians being more likely than non-underrepresented peers to experience burnout, we found that, to the contrary, underrepresented physicians had comparatively lower frequencies of emotional exhaustion and depersonalization. Our findings are consistent with those of studies among family medicine residents and physicians in Texas and residents in South Carolina, and a national study of physicians in all specialties, which also found lower rates of burnout among underrepresented groups. ${ }^{19-21}$ These findings suggest that underrepresented individuals who have succeeded in becoming physicians may have particular resilience related to a sense of social mission or related personal characteristics that protects against burnout. $^{34}$

Consistent with other studies, we found that underrepresented family physicians tended to practice in communities that were more racially and ethnically diverse than the counties in which non-underrepresented physicians practiced. ${ }^{23,27}$ For physicians in our study, practicing in a county with greater diversity indirectly led to experiencing depersonalization less frequently. Practicing in more diverse counties mediated a portion of the overall effect of being an underrepresented family physician on the frequency of experiencing depersonalization. Our findings are consistent with broader social science literature suggesting that racial and ethnic diversity in a community has a beneficial effect on many health and social outcomes for minority populations. ${ }^{46-49}$ Similarly, in 
organizational settings, a more racially and ethnically diverse workforce and climate has been found to be associated with a variety of positive outcomes. ${ }^{50}$ The diversity index (DI) captures a more nuanced aspect of population diversity than simply the proportion of a particular racial-ethnic minority group (eg, Blacks/ African Americans) in a population. The DI is closely related to the cultural diversification concept, which captures the heterogeneity of a community's racial and ethnic composition, ${ }^{51}$ and reflects a dimension of social diversity different from merely comparing how many residents belong to a distinct group. Our findings suggest that practicing in a diverse community is fulfilling professional or personal goals to a greater degree for underrepresented physicians than for non-underrepresented physicians, because the protective effect of diversity was stronger within the former group and not significant in the latter group (analyses reported in https://bit.ly/burnout_familymed). ${ }^{52}$

We also found that underrepresented family physicians were one-half as likely as their non-underrepresented counterparts to practice obstetrics. Contrary to a recent study reporting a protective effect of obstetrical practice on burnout among recent family medicine residency graduates, ${ }^{15}$ but in line with a more recent report, ${ }^{53}$ we found in our sample that included moreexperienced family physicians that obstetrical practice led to reporting more frequent depersonalization.

The lower engagement in obstetrical practice among underrepresented physicians in our study population may have indirectly led them to report less frequent depersonalization. The divergent findings on the relation between obstetrical practice and burnout from our study and from the study of Weidner et $\mathrm{a}^{15}$ suggest that scope of practice may have a different meaning for physician satisfaction with work and sense of personal accomplishment, depending on the developmental stage of a family physician's career.

Our study has several limitations. Although our sample was reasonably representative of US family physicians in all career stages as it was drawn from 2 survey cohorts, those who seek board recertification may differ from the minority who do not. We did not weight the samples to reflect the relative distribution of recent residency graduates and recertifying physicians in the overall national population of US family physicians. Variables such as age and sex that were included as covariates in our analyses adjust for some of the key demographic differences in the sample cohorts, such as younger mean age and a higher proportion of women among the NGS respondents. We did not adjust for the role of other potentially relevant factors for burnout, such as practice setting, care teams models, and work hours. All study measures except the DI measure were based on physician report. The county-level DI may not reflect the racial and ethnic mix of patients served by the respondent at their practice address. Although the single-item self-reported measures of emotional exhaustion and depersonalization have been shown to have construct and predictive validity, ${ }^{35}$ they are not as comprehensive as the full Maslach Burnout Inventory subscales. We pooled underrepresented physicians together into a single grouping. There is a commonality among these physicians in terms of being underrepresented in medicine, but we acknowledge that there is great heterogeneity of life experience, culture, and social characteristics across the specific racial-ethnic groups within the underrepresented cluster as well as within each specific group. Our sample size was too small to afford sufficient statistical power to allow us to examine each specific racial-ethnic group separately in our models. Moreover, exploratory mediation analyses with cross-sectional data should be confirmed with longitudinal data that capture the proper causal sequence of events. ${ }^{54}$

Our findings have several policy implications. At a time when there is growing recognition in the United States of the depth of systemic racism and its harmful effects on the well-being of people of color, it is reassuring to know that underrepresented family physicians are not experiencing a higher degree of burnout than their non-underrepresented counterparts, and if anything, appear to be experiencing less. Understanding the attributes of underrepresented physicians that may protect against burnout, such as a greater social mission orientation and empathy born from experiences of discrimination, may provide insights for developing a physician workforce more resilient to the many forces predisposing to burnout. ${ }^{55}$ For example, medical schools might want to measure these types of protective attributes in all of their applicants, irrespective of applicants' race and ethnicity, and factor those assessments into admissions decisions and ensure that their curricula and culture reinforce those positive attributes. Finally, the case for greater racial and ethnic diversity in the physician workforce has been argued on the basis of several rationales, including addressing historical discrimination, enhancing the educational climate for all learners, and producing a physician workforce more responsive to the needs of underserved populations. ${ }^{56,57}$ Added to those rationales may be a physician workforce less susceptible to burnout. Physician burnout is a known predictor of undesirable workforce outcomes, such as job turnover, which interrupts continuity of care, ${ }^{7}$ and may also be associated with lower quality of care. ${ }^{11}$ The lower burnout observed among underrepresented family physicians may thus be an asset for the health care system as a whole. 
In summary, we found that family physicians underrepresented in medicine report experiencing less frequent emotional exhaustion and depersonalization than their non-underrepresented counterparts. The total effect on depersonalization was partly mediated by the greater likelihood of underrepresented physicians vs non-underrepresented physicians of practicing in more racially and ethnically diverse counties, and their lower likelihood of practicing obstetrics.

\section{To read or post commentaries in response to this article, go to https://www.AnnFamMed.org/content/19/4/342/tab-e-letters.}

Key words: burnout, professional; job satisfaction; occupational stress; race; ethnicity; racism; social environment; physicians, family; primary care

Submitted January 22, 2020; submitted, revised, November 14, 2020; accepted January 22, 2021.

Acknowledgments: The authors thank Lars Peterson and Zach Morgan of the ABFM for preparing and sharing the data with us.

\section{References}

1. Levey RE. Sources of stress for residents and recommendations for programs to assist them. Acad Med. 2001;76(2):142-150.

2. Maslach C, Jackson SE, Leiter MP. Maslach Burnout Inventory Manual. Consulting Psychologists Press; 1996.

3. Shanafelt TD, West CP, Sinsky C, et al. Changes in burnout and satisfaction with work-life integration in physicians and the general US working population between 2011 and 2017. Mayo Clinic Proceedings. 2019;94(9):1681-1694.

4. Lee FJ, Stewart M, Brown JB. Stress, burnout, and strategies for reducing them: what's the situation among Canadian family physicians? Can Fam Physician. 2008;54(2):234-235.

5. Soler JK, Yaman H, Esteva M, et al; European General Practice Research Network Burnout Study Group. Burnout in European family doctors: the EGPRN study. Fam Pract. 2008;25(4):245-265.

6. Lacy BE, Chan JL. Physician burnout: the hidden health care crisis. Clin Gastroenterol Hepatol. 2018;16(3):311-317.

7. Willard-Grace R, Knox M, Huang B, Hammer H, Kivlahan C, Grumbach K. Burnout and health care workforce turnover. Ann Fam Med. 2019;17(1):36-41.

8. Dewa CS, Loong D, Bonato S, Thanh NX, Jacobs P. How does burnout affect physician productivity? A systematic literature review. BMC Health Serv Res. 2014;14:325.

9. Dewa CS, Loong D, Bonato S, Trojanowski L. The relationship between physician burnout and quality of healthcare in terms of safety and acceptability: a systematic review. BMJ Open. 2017;7(6): e015141.

10. Hall LH, Johnson J, Watt I, Tsipa A, O'Connor DB. Healthcare staff wellbeing, burnout, and patient safety: a systematic review. PLOS One. 2016;11(7):e0159015.

11. Salyers MP, Bonfils KA, Luther $L$, et al. The relationship between professional burnout and quality and safety in healthcare: a metaanalysis. J Gen Intern Med. 2017;32(4):475-482.

12. Anagnostopoulos F, Liolios E, Persefonis G, Slater J, Kafetsios K, Niakas D. Physician burnout and patient satisfaction with consultation in primary health care settings: evidence of relationships from a one-with-many design. J Clin Psychol Med Settings. 2012;19(4): 401-410.

13. Haas JS, Cook EF, Puopolo AL, Burstin HR, Cleary PD, Brennan TA. Is the professional satisfaction of general internists associated with patient satisfaction? J Gen Intern Med. 2000;15(2):122-128.
14. Rassolian M, Peterson LE, Fang B, et al. Workplace factors associated with burnout of family physicians. JAMA Intern Med. 2017; 177(7):1036-1038.

15. Weidner AKH, Phillips RL Jr, Fang B, Peterson LE. Burnout and scope of practice in new family physicians. Ann Fam Med. 2018; 16(3):200-205.

16. De Marchis E, Knox M, Hessler D, et al. Physician burnout and higher clinic capacity to address patients' social needs. J Am Board Fam Med. 2019;32(1):69-78.

17. Patel RS, Bachu R, Adikey A, Malik M, Shah M. Factors related to physician burnout and its consequences: a review. Behavioral Sciences. 2018;8(11):98.

18. Eden AR, Jabbarpour Y, Morgan ZJ, Wilkinson E, Peterson LE. Burnout among family physicians by gender and age. J Am Board Fam Med. 2020;33(3):355-356.

19. Buck K, Williamson M, Ogbeide S, Norberg B. Family physician burnout and resilience: a cross-sectional analysis. Fam Med. 2019; 51(8):657-663.

20. Michels PJ, Probst JC, Godenick MT, Palesch Y. Anxiety and anger among family practice residents: a South Carolina family practice research consortium study. Acad Med. 2003;78(1):69-79.

21. Garcia LC, Shanafelt TD, West CP, et al. Burnout, depression, career satisfaction, and work-life integration by physician race/ethnicity. JAMA Netw Open. 2020;3(8):e2012762.

22. Association of American Medical Colleges. Underrepresented in medicine definition. Published 2019. Accessed Sep 28, 2019. https://www.aamc.org/what-we-do/mission-areas/diversity-inclusion/ underrepresented-in-medicine

23. Xierali IM, Nivet MA. The racial and ethnic composition and distribution of primary care physicians. J Health Care Poor Underserved. 2018;29(1):556-570.

24. Cantor JC, Miles EL, Baker LC, Barker DC. Physician service to the underserved: implications for affirmative action in medical education. Inquiry. 1996;33(2):167-180.

25. Dyrbye LN, Massie FS Jr, Eacker A, et al. Relationship between burnout and professional conduct and attitudes among US medical students. JAMA. 2010;304(11):1173-1180.

26. Garcia AN, Kuo T, Arangua L, Pérez-Stable EJ. Factors associated with medical school graduates' intention to work with underserved populations: policy implications for advancing workforce diversity. Acad Med. 2018;93(1):82-89.

27. Walker KO, Moreno G, Grumbach K. The association among specialty, race, ethnicity, and practice location among California physicians in diverse specialties. J Natl Med Assoc. 2012;104(1-2):46-52.

28. Stevenson HC, McNeil JD, Herrero-Taylor T, Davis GY. Influence of perceived neighborhood diversity and racism experience on the racial socialization of Black youth. J Black Psychol. 2005;31(3): 273-290.

29. White K, Borrell LN. Racial/ethnic neighborhood concentration and self-reported health in New York City. Ethn Dis. 2006;16(4):900-908.

30. Selye H. Stress in Health and Disease. Butterworth-Heinemann; 1976.

31. Van Emmerik I, Jawahar I, Stone T. The moderating effects of burnout on the relationship between altruism and helping behaviours. Work Stress. 2005;19(1):93-100.

32. Hooker SA, Post RE, Sherman MD. Awareness of meaning in life is protective against burnout among family physicians: a CERA study. Fam Med. 2020;52(1):11-16.

33. Baumeister RF, Bratslavsky E, Muraven M, Tice DM. Ego depletion: is the active self a limited resource? J Pers Soc Psychol. 1998;74(5): 1252-1265.

34. Dyrbye LN, Burke SE, Hardeman RR, et al. Notice of retraction and replacement: Dyrbye, et al. Association of clinical specialty with symptoms of burnout and career choice regret among us resident physicians. JAMA. 2018;320(11):1114-1130. JAMA. 2019;321(12): 1220-1221. 
35. West CP, Dyrbye LN, Satele DV, Sloan JA, Shanafelt TD. Concurrent validity of single-item measures of emotional exhaustion and depersonalization in burnout assessment. J Gen Intern Med. 2012;27(11): 1445-1452.

36. West CP, Dyrbye LN, Sloan JA, Shanafelt TD. Single item measures of emotional exhaustion and depersonalization are useful for assessing burnout in medical professionals. J Gen Intern Med. 2009;24(12): 1318-1321.

37. Grumbach K, Knox M, Huang B, Hammer H, Kivlahan C, WillardGrace R. A longitudinal study of trends in burnout during primary care transformation. Ann Fam Med. 2019;17(Suppl 1):S9-S16.

38. Adler-Milstein J, Zhao W, Willard-Grace R, Knox M, Grumbach K. Electronic health records and burnout: time spent on the electronic health record after hours and message volume associated with exhaustion but not with cynicism among primary care clinicians. J Am Med Inform Assoc. 2020;27(4):531-538.

39. PolicyMap. Published 2019. Accessed May 7, 2019. https://www. policymap.com

40. Bentler PM, Stein JA. Structural equation models in medical research. Stat Methods Med Res. 1992;1(2):159-181.

41. VanderWeele TJ. Principles of confounder selection. Eur J Epidemiol. 2019;34(3):211-219.

42. Hayduk LA. Structural Equation Modeling With LISREL: Essentials and Advances. Johns Hopkins University Press; 1987.

43. Bollen KA. Structural Equations With Latent Variables. John Wiley and Sons; 1989.

44. Bailey ZD, Krieger N, Agénor M, Graves J, Linos N, Bassett MT. Structural racism and health inequities in the USA: evidence and interventions. Lancet. 2017;389(10077):1453-1463.

45. Dyrbye LN, Thomas MR, Eacker A, et al. Race, ethnicity, and medical student well-being in the United States. Arch Intern Med. 2007; 167(19):2103-2109.

46. Dawson AZ, Walker RJ, Campbell JA, Egede LE. Effect of perceived racial discrimination on self-care behaviors, glycemic control, and quality of life in adults with type 2 diabetes. Endocrine. 2015;49(2): 422-428.
47. Neal ZP, Neal JW. The (in)compatibility of diversity and sense of community. Am J Community Psychol. 2014;53(1-2):1-12.

48. Theil H. Statistical Decomposition Analysis; With Applications in the Social and Administrative Sciences. North-Holland Publishing Company; 1972

49. Walker RJ, Strom Williams J, Egede LE. Influence of race, ethnicity and social determinants of health on diabetes outcomes. Am J Med Sci. 2016;351(4):366-373.

50. Hofhuis J, van der Rijt PG, Vlug M. Diversity climate enhances work outcomes through trust and openness in workgroup communication. Springerplus. 2016;5(1):714.

51. Brodsky AE. Bridging the dialectic: Diversity, psychological sense of community, and inclusion. Am J Community Psychol. 2017;59(3-4): 269-271.

52. Dyrbye LN, Thomas MR, Huschka MM, et al. A multicenter study of burnout, depression, and quality of life in minority and nonminority US medical students. Mayo Clinic Proc. 2006;81(11):1435-1442.

53. Barreto TW, Eden A, Brock A. The impact of practicing obstetrics on burnout among early-career family physicians. Fam Med. 2020; 52(6):408-413.

54. Cole DA, Maxwell SE. Testing mediational models with longitudinal data: questions and tips in the use of structural equation modeling. J Abnorm Psychol. 2003;112(4):558-577.

55. National Academies of Sciences Engineering and Medicine. Taking Action Against Clinician Burnout: A Systems Approach to Professional Well-Being. National Academies Press; 2019.

56. Grumbach K, Mendoza R. Disparities in human resources: addressing the lack of diversity in the health professions. Health Aff (Millwood). 2008;27(2):413-422.

57. Saha S, Shipman S. The Rationale for Diversity in Health Professions: A Review of the Evidence. US Department of Health and Human Services and Services Administration, HRSA; 2006. 